See discussions, stats, and author profiles for this publication at:

https://www.researchgate.net/publication/265380579

\title{
The Medicare Electronic Health Records (EHR) Incentive Program: First Year Adoption Response from Inpatient Hospitals
}

Article in Journal of Organizational Computing and Electronic Commerce · October 2014 DOI: $10.1080 / 10919392.2014 .956601$

CITATIONS

0

2 authors:

\section{Rajesh Mirani}

University of Baltimore

28 PUBLICATIONS 550 CITATIONS

SEE PROFILE
READS

47 


\title{
THE MEDICARE ELECTRONIC HEALTH RECORDS (EHR) INCENTIVE PROGRAM: FIRST-YEAR ADOPTION RESPONSE FROM INPATIENT HOSPITALS
}

\author{
$\underline{\text { Rajesh Mirani }}^{1}$ and Anju Harpalani ${ }^{2}$ \\ ${ }^{1}$ Merrick School of Business, University of Baltimore, Baltimore, Maryland, USA \\ ${ }^{2}$ Booz Allen Hamilton, Rockville, Maryland, USA
}

This study investigates electronic health records (EHR) adoption among inpatient hospitals in response to the first operational year of the Medicare EHR Incentive Program. Profile analysis of public attestation datasets finds both system adoption rates and implemented functionalities to have been significantly influenced by the incentive program's attributes. Key dates and periods in the program's well-publicized timeline were usually accompanied by spikes in the number of attested systems and/or dips in advanced functionalities. The implication is that hospitals have responded to the program by swifty implementing EHR systems with capabilities just sufficient to meet program requirements, in order to be able to promptly file attestations and thus claim their incentive payments. The program therefore appears to have yielded mixed results. While it seems to have induced more hospitals to acquire EHR systems, the implemented systems generally possess minimal functionalities, suggesting that adopters have leveraged the program's rules in order to maximize their own short-term gains.

Keywords: EHR; electronic health records; EMR; electronic medical records; incentive programs; IT adoption and diffusion; IT implementation and usage; meaningful use

\section{INTRODUCTION}

Electronic health records (EHR), also known as electronic medical records (EMR), have lately been a subject of much interest. It is envisioned that their widespread diffusion and usage among a critical mass of hospitals and other health care providers holds the potential to generate a series of cascading benefits throughout the public health system. Expected benefits include more effective information sharing, reduced errors, greater patient compliance, higher customer satisfaction, lower health care costs, and better overall clinical outcomes (Furukawa, Raghu, \& Shao 2010; Hillestad et al. 2005; Hochstadt and Keyt 2009; Kazley, Diana, and Menachemi 2011 Song et al. 2011). To that end, and given that health care providers have historically been lukewarm to records automation (DesRoches et al. 2012; Wolf, Harvell, \& Jha 2012), federal and state governments have

Address correspondence to Rajesh Mirani, Merrick School of Business, University of Baltimore, 11 W. Mt. Royal Avenue, Baltimore, MD 21201, USA. E-mail: rmirani@ubalt.edu

Color versions of one or more of the figures in the article can be found online at www.tandfonline. com/hoce. 
offered a variety of inducements for them to adopt EHR, by means of tax breaks as well as carefully targeted initiatives.

This article reports the market's response to one such initiative. Specifically, it measures the response of hospitals to the Medicare EHR Incentive Program, instituted by the Centers for Medicare and Medicaid Services (CMS). Under Stage 1 of this program, CMS has been providing monetary incentives to hospitals that attest to having successfully met specific "meaningful use" criteria with implemented EHR functionalities. Because this stipulation makes no distinction between hospitals with and without preexisting EHR systems, the success of the incentive program in terms of encouraging more hospitals to adopt EHR is open to question. The overall goal of the study, therefore, is to assess whether the program has actually influenced hospitals without EHR to adopt such systems.

\section{CONTEXT AND RESEARCH PROPOSITION}

CMS rolled out this \$20 billion program under the Health Information Technology for Economic and Clinical Health Act (HITECH Act), the stated goal of which is to improve the health care system's efficiency and effectiveness through the wider adoption of EHR (Hamelburg 2009). According to Stage 1 of the EHR Incentive Program, cash incentives are to be paid to providers - both eligible professionals (EPs) and eligible hospitals (EHs) - upon successful implementation of certified EHR products, and formal attestation of their "meaningful use" to CMS. The incentive programs were originally announced in 2009 and 2010. Registration and attestation officially began in 2011. To date, hundreds of EPs and EHs have submitted formal attestations to the implementation and meaningful use of certified EHR products, and have received cash incentives for the same.

CMS defines "meaningful use" as the use of certified EHR technology: (a) in a meaningful manner, (b) for the electronic exchange of health information with the objective of improved health care quality, and (c) to report specific clinical quality measures (CQMs). The program defines separate, increasingly stringent sets of criteria to assess meaningful use in each of three stages over a five-year period, and sets aside incentive payments for each stage, beginning in 2011, and culminating in 2016. For each stage, distinctly different criteria sets have been defined for EPs (i.e., nonhospital, ambulatory care providers) and EHs (i.e., inpatient hospitals). The Stage 1 meaningful use criteria set for hospitals is comprised of 47 items and associated measures, all centered around the use of EHR for the elementary purpose of "data capture and sharing" (CMS 2010).

The certification of EHR products, overseen by the Office of the National Coordinator for Health Information Technology (ONC), follows these criteria sets. Thus, each product approved for use in inpatient hospitals is certified as a "complete" EHR, or a "modular" EHR. An EHR product is certified as complete if its functionalities and capabilities correspond to every single one of 23 "general criteria" and 9 "inpatient criteria" in the Stage 1 criteria set. Alternatively, it is certified as modular if its features correspond to some, but not all, of the 32 combined criteria under these two categories (Health Information Technology 2010).

To demonstrate meaningful use and receive incentives in Stage 1, a hospital must attest to having acquired and implemented either complete or modular EHR, and also to having applied this technology and met 18 of 23 objectives, over a 90-day reporting period-all 13 objectives from a "core set," plus any five out of ten objectives from a "menu set." The 32 criteria mentioned earlier constitute operational measures of these objectives (CMS 2010). 
Table 1 Research context-American Recovery and Reinvestment Act, 2009.

- Eligible Hospitals (EHs) that adopt certified EHR technology and use it to achieve specific "meaningful use" objectives will qualify for annual incentive payments from the Centers for Medicare and Medicaid Services (CMS)

- Three stage evolution of meaningful use:

1. Stage 1: Data capture and sharing $\leftarrow($ FOCUS OF STUDY $)$

2. Stage 2: Advance clinical processes

3. Stage 3: Improved outcomes

- To receive incentives in Stage 1, a hospital must attest to having met 18 out of 23 objectives/measures, over a 90-day reporting period

1. 13 objectives in core set-must meet all 13

2. 10 objectives in menu set-must meet any 5 (remaining 5 may be deferred)

- CMS maintains records of all attestations

Table 1 summarizes the research context.

This study attempts to discern evolving patterns of functionalities from the attestations of modular EHR products by hospitals, with the specific intent of searching for a possible connection between the incentive program and the actions of hospitals in response to this program. Such a linkage will help shed light on the effectiveness of the program. The overall objective is to determine whether and how the program has successfully influenced the adoption and diffusion of EHR technologies in the inpatient health care arena. A key assumption is that attestations of EHR products collectively represent a reasonable proxy for measuring EHR adoption and diffusion. It is further reasoned that because hospitals' changing responses to various milestones embedded in the program's timeline will likely be reflected in variations among acquired/attested product functionalities and features, attempting to correlate these variations with key points in the program's timeline will provide insights into the program's influence on the intended market.

Complete EHRs have not been included in this study for two reasons. First, hospitals have a known bias for modular EHRs (in contrast to other health care settings, such as ambulatory clinics, which largely prefer complete EHRs). Second, the inclusion of complete EHRs in the study would not have yielded any useful patterns as, by definition, such products meet the full range of possible EHR functionalities.

Research Proposition: Over a period of one year since its inception, the CMS Medicare EHR Incentive Program has significantly influenced the adoption of EHR systems in inpatient hospitals.

\section{METHODOLOGY}

The first source of information for the analysis was a dataset of attestations made by health care providers to the CMS, for meaningful use of certified EHR products. This Excel file (mu_report.xlsx) was downloaded from the federal government data Web site located at https://explore.data.gov/download/eybk-7w2b/XLS. It contained a detailed listing of all attestations made by eligible providers and eligible hospitals since the inception of the Medicare and Medicaid incentive programs (April 2011 onwards). Each of the 80,000plus records in this file pertained to the attestation of a single certified EHR product, 
Table 2 Contents of EHR product attestations file mu_report.xlsx.

\begin{tabular}{|c|c|c|}
\hline Variable Name & CMS Definition & How Utilized in Present Study \\
\hline Vendor Name & [Name of EHR vendor] & Basis for cross-referencing attestation \\
\hline EHR Product Name & [Name of EHR product] & information with product feature \\
\hline EHR Product Version & [Version of EHR product] & $\begin{array}{l}\text { information available through Certified } \\
\text { Health Information Technology (HIT) } \\
\text { Product List at http://oncchpl.force.com/ } \\
\text { ehrcert }\end{array}$ \\
\hline Product Classification & $\begin{array}{l}\text { [Whether product meets all } \\
\text { Meaningful Use (MU) } \\
\text { requirements (Complete) or meets } \\
\text { only part of the MU requirements } \\
\text { (Modular)] }\end{array}$ & Analysis limited to "Modular" field values \\
\hline Product Setting & $\begin{array}{l}\text { [Practice setting for which product is } \\
\text { designed for (Ambulatory or } \\
\text { Inpatient)] }\end{array}$ & Analysis limited to "Inpatient" field values \\
\hline $\begin{array}{l}\text { Attestation Month } \\
\text { Attestation Year }\end{array}$ & $\begin{array}{l}\text { [Month that the provider successfully } \\
\text { attested to MU] } \\
\text { [Year that the provider successfully } \\
\text { attested to MU] }\end{array}$ & $\begin{array}{l}\text { Categorization basis for month-by-month } \\
\text { computations of average factor strengths } \\
\text { denoting features of attested/installed } \\
\text { EHR }\end{array}$ \\
\hline Business State/Territory & $\begin{array}{l}\text { [Business location of provider who } \\
\text { successfully attested to } M U \\
\text { (state/territory)] }\end{array}$ & (Discarded) \\
\hline Provider Type & $\begin{array}{l}\text { [Whether attestor was an eligible } \\
\text { professional }(E P) \text { or eligible } \\
\text { hospital }(E H)]\end{array}$ & Analysis limited to "EH" field values \\
\hline Specialty & [Specialty or provider type] & (Discarded) \\
\hline Program Year & [Year of EHR Incentive Program] & (Discarded) \\
\hline Payment Year & $\begin{array}{l}\text { [Payment year of EHR Incentive } \\
\text { Program] }\end{array}$ & (Discarded) \\
\hline Program Type & $\begin{array}{c}\text { [Whether the attestor registered } \\
\text { under Medicare or Medicaid] }\end{array}$ & Analysis limited to "Medicare" field values \\
\hline ID & [Unique ID for each attestor] & $\begin{array}{l}\text { Nonidentifying primary key for } \\
\text { cross-referencing and data preparation }\end{array}$ \\
\hline
\end{tabular}

Adapted from Data Dictionary, CMS Medicare and Medicaid EHR Incentive Program: Electronic Health Record Products Used for Attestation, The Office of the National Coordinator for Health Information Technology (http://www.healthit.gov/sites/default/files/pdf/HealthDataGov\%20MU\%20Attest\%20Data\%20Dictionary.pdf).

as implemented by a single provider. Columns in the spreadsheet pertained to vendor name, product and version attested, product classification (complete vs. modular products), product setting (ambulatory vs. inpatient products), provider type (EP vs. EH), attestation month/year, etc. A complete listing of these fields is provided in Table 2.

The second source was a searchable Certified Health Information Technology (HIT) Product List at http://oncchpl.force.com/ehrcert, made available by the Office of the National Coordinator for Health Information Technology (ONC) (see Figures 1 and 2). This database listed the specific certification criteria met by each certified EHR product. The superset of all such criteria was comprised of 47 items, including 23 general criteria, 9 inpatient criteria, and 15 CQMs. The 32 criteria that make up the first two of these three categories are listed in Table 3. CQMs are excluded from the table (and this study) because the first-year meaningful use definition for hospitals stipulated only that that they be reported, but did not specify any required minimum performance levels along these measures. 


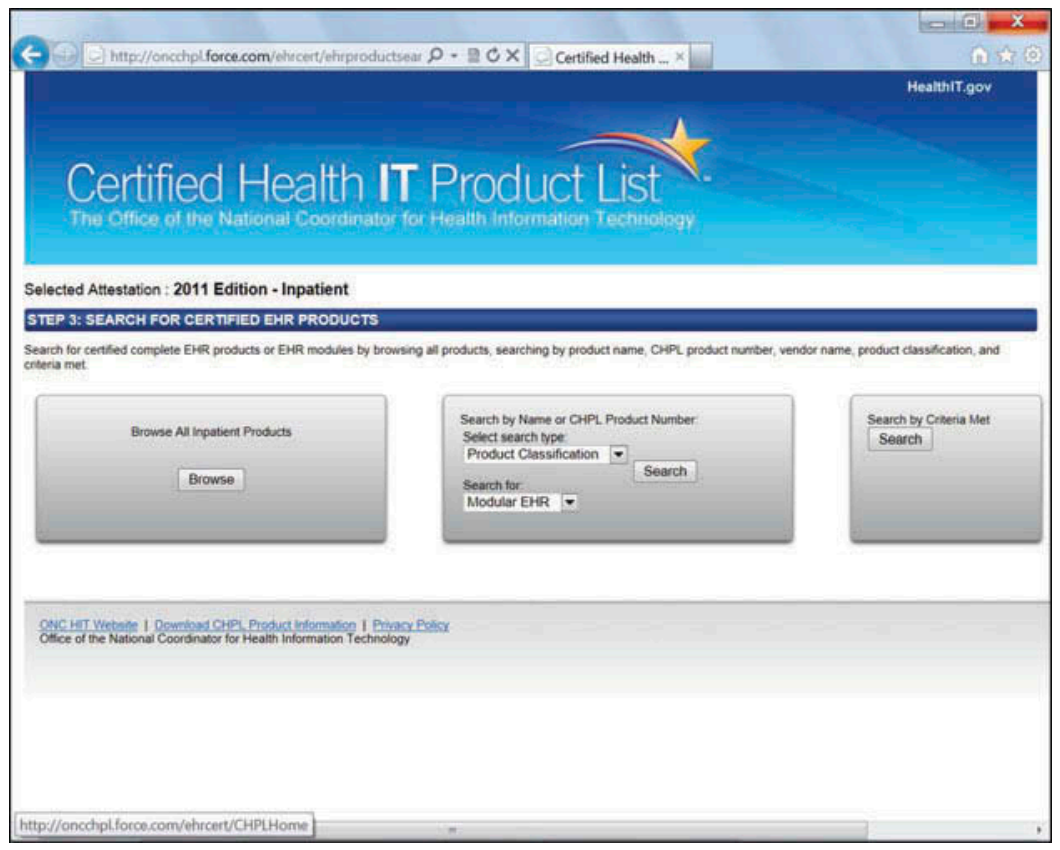

Figure 1 Searchable certified EHR technology database.

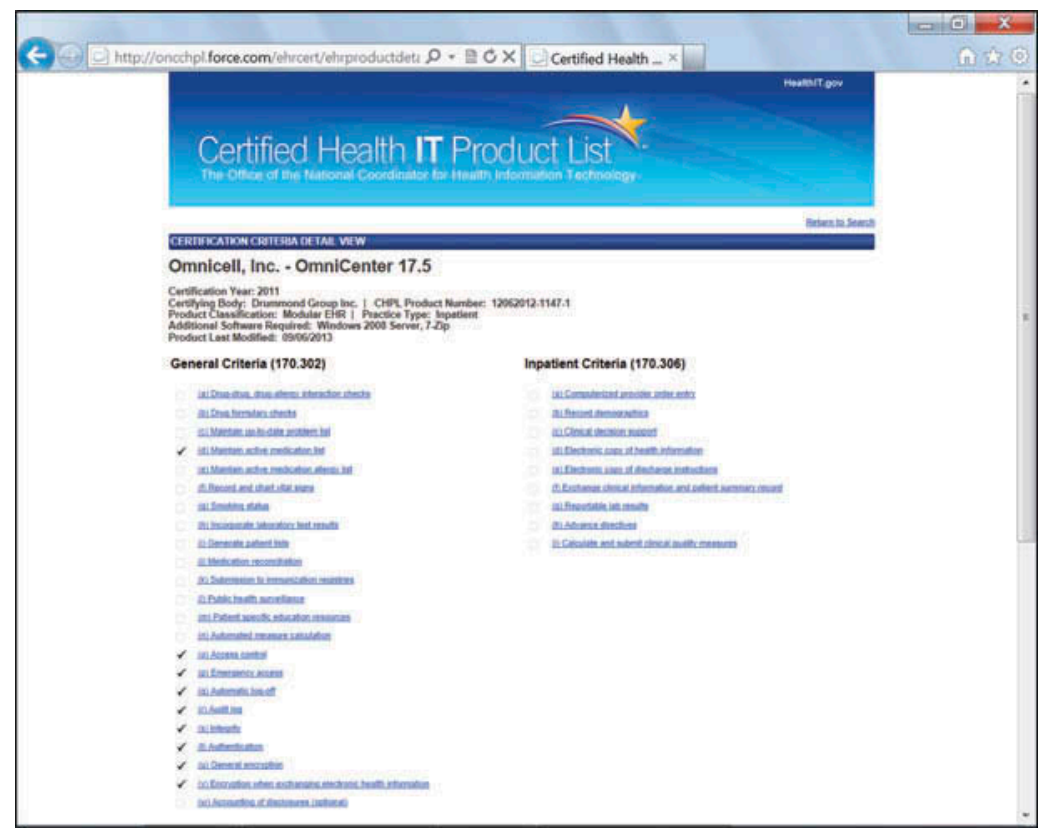

Figure 2 Sample search of certified EHR database. 
Table 3 EHR product certification criteria (general and inpatient categories only).

\begin{tabular}{|c|c|}
\hline General Criteria & Inpatient Criteria \\
\hline $\begin{array}{l}\text { (a) Drug-drug, drug-allergy interaction checks } \\
\text { (b) Drug formulary checks } \\
\text { (c) Maintain up-to-date problem list } \\
\text { (d) Maintain active medication list } \\
\text { (e) Maintain active medication allergy list } \\
\text { (f) Record and chart vital signs } \\
\text { (g) Smoking status } \\
\text { (h) Incorporate laboratory test results } \\
\text { (i) Generate patient lists } \\
\text { (j) Medication reconciliation } \\
\text { (k) Submission to immunization registries } \\
\text { (l) Public health surveillance } \\
\text { (m) Patient specific education resources } \\
\text { (n) Automated measure calculation } \\
\text { (o) Access control } \\
\text { (p) Emergency access } \\
\text { (q) Automatic log-off } \\
\text { (r) Audit log } \\
\text { (s) Integrity } \\
\text { (t) Authentication } \\
\text { (u) General encryption } \\
\text { (v) Encryption when exchanging electronic } \\
\text { health information } \\
\text { (w) Accounting of disclosures }\end{array}$ & $\begin{array}{l}\text { (a) Computerized provider order entry } \\
\text { (b) Record demographics } \\
\text { (c) Clinical decision support } \\
\text { (d) Electronic copy of health information } \\
\text { (e) Electronic copy of discharge instructions } \\
\text { (f) Exchange clinical information and patient summary record } \\
\text { (g) Reportable lab results } \\
\text { (h) Advance directives } \\
\text { (i) Calculate and submit clinical quality measures }\end{array}$ \\
\hline
\end{tabular}

Source: The Office of the National Coordinator for Health Information Technology (http://healthit.hhs.gov/ media/MU/n508/MU-(EH-CAH)_SCC-InpatientOnlyGrid.pdf).

To prepare the data for analysis, a three-way filter was first applied to the mu_report.xlsx Excel file, by selecting attestations made by eligible hospitals but not eligible providers, and within this selection, including only those records pertaining to modular, inpatient products but not complete or ambulatory ones. This filter resulted in the elimination of most records from the original file, leaving a much smaller selection of 549 data points as the basis for the analysis. Five fields were subsequently retained in the selected records. These fields were vendor name, product name, product version, month of attestation, and year of attestation. Next, this narrowed dataset was merged with the certified product list from the second source, by means of a database join. The merger of these two sources resulted in cross-referenced information, with attestation month and year obtained from the first source, and product certification criteria obtained from the second. This merged dataset was now ready for analysis.

\section{ANALYSIS AND RESULTS}

A preliminary objective of the analysis was to reduce the superset of 32 features collectively present in modular inpatient EHR products implemented by hospitals, into fewer, cohesive sets of feature categories. Deriving these categories would enable the fulfillment of the study's major objective, which was to detect broad, evolving patterns in the features and functionalities of EHR systems implemented by various hospitals from one month to the next. To meet the preliminary objective, an exploratory factor analysis of the 32 general and 
inpatient criteria was carried out, using the 81 products attested by hospitals as data points. The 32 superset criteria were treated as dummy variables; that is, they were assigned values of 1 wherever a given product was certified as possessing the corresponding functionalities, and 0 where such functionalities were not present in the product.

Pearson correlations were employed as the basis for a principal factor analysis as the extraction method, with squared multiple correlations to determine initial commonalities, and an "automatic" setting to determine the optimal number of factors, based on the scree plot. Stop conditions were specified as 0.0001 convergence, and 50 iterations. Five factors emerged from 23 iterations, with four of the five factors comprised of two or more items, whose Cronbach's alpha values ranged from 0.785 to 0.982 . The five factors or feature categories were interpreted as follows: Factor 1: CORE EHR; Factor 2: SECURITY; Factor 3: CONTROLS; Factor 4: CONNECTIVITY; and Factor 5: CLINICAL MEASURES. Twenty items (certification criteria) loaded on CORE EHR, four on SECURITY, three on CONTROLS, four on CONNECTIVITY, and one on CLINICAL MEASURES. The extraction of these factors successfully accomplished the study's preliminary objective. Table 4 lists the factors and item loadings.

The second half of the analysis focused on the study's main objective, which was to ascertain hospitals' evolving responses to the Medicare EHR incentive program. This was accomplished as follows. First, the five extracted factors were applied to the 549 attestation records, in order to characterize hospital-implemented EHR systems in terms of broad functionalities. To do so, individual item scores (i.e., the 0 s and $1 \mathrm{~s}$ ) under each factor

Table 4 Factor analysis item loadings.

\begin{tabular}{|c|c|c|c|}
\hline Criteria & $\begin{array}{c}\text { Item } \\
\text { Loadings }\end{array}$ & Criteria & $\begin{array}{c}\text { Item } \\
\text { Loadings }\end{array}$ \\
\hline FACTOR 1: CORE EHR & & FACTOR 2: SECURITY & \\
\hline Drug-drug, drug-allergy interaction checks & 0.930 & Audit $\log$ & -0.699 \\
\hline Drug formulary checks & 0.930 & Integrity & -0.751 \\
\hline Maintain up-to-date problem list & 0.951 & General encryption & -0.728 \\
\hline Maintain active medication list & 0.939 & $\begin{array}{l}\text { Encryption when exchanging electronic } \\
\text { health information }\end{array}$ & -0.631 \\
\hline Maintain active medication allergy list & 0.973 & & \\
\hline Record and chart vital signs & 0.943 & & \\
\hline Smoking status & 0.964 & FACTOR 3: CONTROLS & \\
\hline Incorporate laboratory test results & 0.935 & Access control & -0.964 \\
\hline Generate patient lists & 0.758 & Automatic log-off & -0.653 \\
\hline Medication reconciliation & 0.897 & Authentication & -0.964 \\
\hline Patient specific education resources & 0.833 & & \\
\hline Automated measure calculation & 0.587 & & \\
\hline Emergency access & 0.590 & FACTOR 4: CONNECTIVITY & \\
\hline Accounting of disclosures & 0.606 & Submission to immunization registries & 0.555 \\
\hline Computerized provider order entry & 0.930 & Public health surveillance & 0.566 \\
\hline Record demographics & 0.964 & $\begin{array}{l}\text { Exchange clinical information and patient } \\
\text { summary record }\end{array}$ & 0.459 \\
\hline Clinical decision support & 0.954 & Reportable lab results & 0.564 \\
\hline Electronic copy of health information & 0.716 & & \\
\hline Electronic copy of discharge instructions & 0.787 & & \\
\hline Advance directives & 0.917 & $\begin{array}{l}\text { FACTOR 5: CLINICAL MEASURES } \\
\text { Calculate and submit clinical quality } \\
\text { measures }\end{array}$ & 0.463 \\
\hline
\end{tabular}


Table 5 Number of attestations and average factor scores, by month.

\begin{tabular}{lcccccc}
\hline & & \multicolumn{5}{c}{ Factor Averages } \\
\cline { 3 - 6 } Month-Year & $\begin{array}{c}\text { Number of } \\
\text { Attestations }\end{array}$ & $\begin{array}{c}\text { Core } \\
\text { EHR }\end{array}$ & Security & Controls & Connectivity & $\begin{array}{c}\text { Clinical } \\
\text { Measures }\end{array}$ \\
\hline Jun-11 & 3 & 0.633 & 1.000 & 1.000 & 0.583 & 0.333 \\
Jul-11 & 29 & 0.691 & 0.974 & 0.989 & 0.534 & 0.448 \\
Aug-11 & 7 & 0.871 & 1.000 & 1.000 & 0.143 & 0.143 \\
Sep-11 & 39 & 0.691 & 0.968 & 0.923 & 0.205 & 0.205 \\
Oct-11 & 185 & 0.392 & 0.931 & 0.746 & 0.330 & 0.308 \\
Nov-11 & 55 & 0.522 & 0.959 & 0.836 & 0.391 & 0.291 \\
Dec-11 & 18 & 0.686 & 1.000 & 1.000 & 0.597 & 0.444 \\
Jan-12 & 13 & 0.454 & 1.000 & 1.000 & 0.365 & 0.231 \\
Feb-12 & 41 & 0.677 & 0.988 & 1.000 & 0.396 & 0.220 \\
Mar-12 & 21 & 0.643 & 1.000 & 1.000 & 0.369 & 0.286 \\
Apr-12 & 21 & 0.476 & 0.857 & 0.952 & 0.226 & 0.095 \\
May-12 & 19 & 0.503 & 0.868 & 1.000 & 0.316 & 0.105 \\
Jun-12 & 98 & 0.560 & 0.950 & 1.000 & 0.410 & 0.347 \\
TOTAL: & 549 & & & & & \\
\hline
\end{tabular}

were averaged out, resulting in the calculation of five "factor strength" scores for each of the 549 attestations. For any attestation, a given factor strength score reflected the extent to which the corresponding EHR product possessed a specific category of functionalities. In the second step, these characterizations were sequenced and summarized by attestation month. To do so, the 549 score sets were reduced to 13 sets by grouping together attestations in common months (beginning in June 2011 and culminating in June 2012), and averaging out each month. In the third and final step, variations within and between the 13 timeordered summary sets were analyzed to detect meaningful change patterns and trends. To do so, the average monthly factor scores were subjected to a profile analysis. The premise of such an analysis was that the presence of a market response would reveal distinctive, meaningful, and changing patterns of attestations over time in terms of the five factors, while the absence of a market response would instead be characterized by nondifferentiated patterns along these factors. Accordingly, a time series line chart was prepared as the basis for the analysis. This chart plots average monthly scores of each of the five factors over the 13month period for which data were available. Table 5 depicts these average monthly factor scores, and Figure 3 shows the resulting line chart.

From the chart, it may be noted that the two factors SECURITY and CONTROLS had uniformly high scores over the recorded period, implying that most installed EHR applications were consistently strong on these two features. Of the other three factors, CORE EHR generally had the higher scores, followed respectively by CONNECTIVITY and CLINICAL MEASURES. Four other observations were particular noteworthy. First, the intensity of the CORE EHR factor saw an upward spike in August 2011, even as CONNECTIVITY and CLINICAL MEASURES dipped steeply. Second, the top three factors, that is, SECURITY, CONTOLS, and CORE EHR saw sharp drops in October 2011, while CONNECTIVITY and CLINICAL MEASURES recovered during that time. Third, every third month following October 2011 was characterized by dips for all five factors. These dips occurred in January 2012 and April 2012. Fourth, February 2012 saw a CORE EHR spike similar to the one in August 2011, in that it diverged considerably from the other factors that either remained flat or dropped somewhat. 


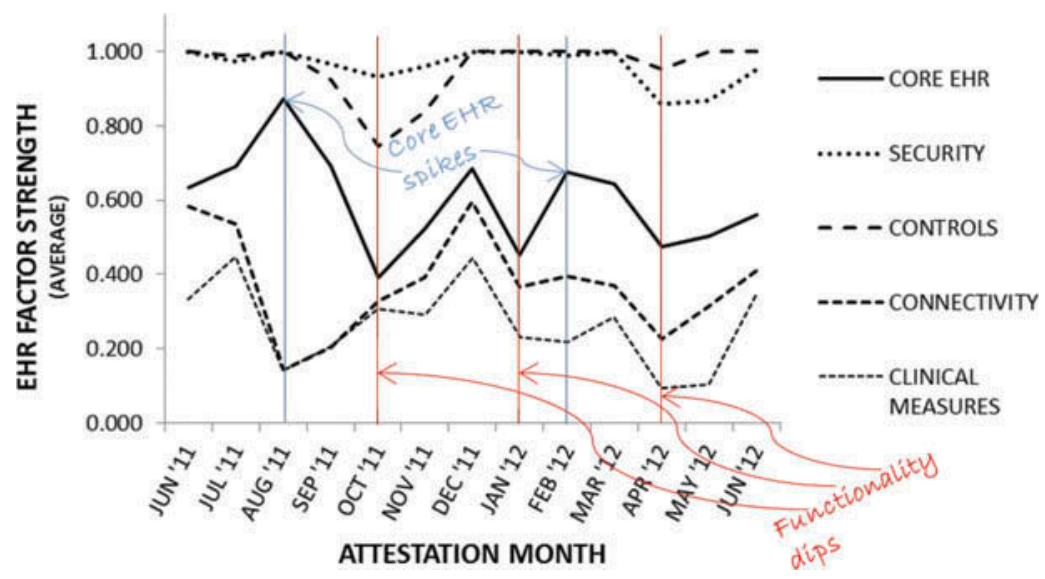

Figure 3 Average monthly factor scores.

To enable the meaningful interpretation of these variations, a profile analysis was conducted to formally test whether there were statistically significant differences among the patterns of the five sets of factor scores over time. In statistical terms, profile analysis is an adaptation of multivariate analysis of variance (MANOVA) to contexts containing multiple dependent variables, assessed using common measures. The research question typically addressed by profile analysis is the test of parallelism, that is, whether the profiles of several groups along a set of variables can be said to be parallel/similar to each other, or generally different. The application of profile analysis in this study represents a well-known extension of the technique called doubly-multivariate design, where multiple dependent variables are assessed at many different points in time (Tabachnick and Fidell 2013).

Two multidimensional tests were employed as part of the profile analysis. The first of these was Wilks' Lambda test (Rao's approximation). Profile analysis looks for parallelism by first computing this statistic and subsequently translating it into an "observed" $F$ statistic. As with regular MANOVA, the latter is said to be "significant" if its value exceeds the critical F-value. An absence of statistical significance would imply that any visible differences between the profiles of the five-factor scores over time could be attributable to randomness. On the other hand, the presence of significance would lend validity to substantive interpretations of differential patterns. The null hypothesis tested here was that the means vectors of the 13 factor patterns (one for each month) were in general not different from each other. A Lambda value of $0.635\left(\mathrm{df}_{1}=60, \mathrm{df}_{2}=2490\right)$ resulted from this

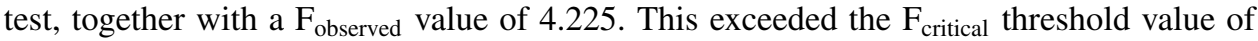
1.324 , with a strong $p$-value of 0.0001 . The null hypothesis was thus rejected, implying the presence of significant differences between the 13 patterns.

The purpose of the second multidimensional test was to pinpoint the specific time periods during which changes in the five-factor vectors were statistically significant, so that contextual interpretations could be ascribed to these changes and time periods with some confidence. This was accomplished by computing between-class (between months) Fisher distance values for each of 78 unique pairs of months. Forty-one of the 78 values were found to be statistically significant at the $0.05 \alpha$-level. Moreover, of the 12 pairs representing consecutive month combinations, five were significant at the $0.05 \alpha$-level. These were July 2011-August 2011, September 2011-October 2011, November 2011-December 2011, 
March 2012-April 2012, and May 2012-June 2012. Table 6 depicts the Fisher statistics and their associated $p$-values.

Table 7 provides an overall summary of the research study, in terms of objectives, research proposition, methodology, and findings.

\section{IMPLICATIONS AND DISCUSSION}

The discovery of five factors among the various EHR features suggests that the attributes of EHR products tend to cluster into distinct categories. Of these, the CORE EHR factor represents the most basic, essential set of functional capabilities. In addition, the consistently high scores for SECURITY and CONTROLS in Table 6 indicate that these two factors represent critical, non-negotiable features, and, because they are in the core requirements, as opposed to the menu requirements, they are therefore present in virtually all EHR products. The remaining two factors, namely, CONNECTIVITY and CLINICAL MEASURES, appear to be comprised of advanced, value-added, optional functionalities. A profile analysis of the five factors, as represented in the 549 EHR product attestations over a 13-month time period, has found the numerous fluctuations in relative factor strengths from one month to the next to be generally statistically significant. In light of this, a closer examination of these variations is justified, which reveals some interesting patterns.

One such meaningful pattern is a sharp divergence in the average monthly strength of the CORE EHR factor from the CONNECTIVITY and CLINICAL factors in August 2011, when the former factor jumped up from its previous monthly average by $26 \%$, as the latter factors fell respectively by $73 \%$ and $68 \%$ in the same month. This divergence and its timing signal intent on the part of hospitals to implement basic EHR functionalities immediately following the announcement of the incentive program, so that attestations could be filed and incentive amounts claimed as soon as possible. Such an explanation is supported by a combination of several facts.

The announcement of the incentive program was made in April 2011, with a reporting requirement of 90-day meaningful use for all year-one attestations. Hospitals that commenced their 90-day period right after this announcement would have completed it in July 2011, and filed their attestations right around August 2011, which is when the divergence occurred. It may be noted that attestations prior to August 2011 did not exhibit this type of a strong divergence between CORE EHR and other, optional features. The reasonable interpretation, therefore, is that attestations prior to August 2011 were from hospitals with mature EHR systems implemented before the regulation was in place, and that the August 2011 attestations came primarily from those hospitals that had set about their 90-day period soon after the April 2011 announcement. Further, the factor divergence is highly instructive in terms of the implementing hospitals' mindset and intent. It suggests that the EHR products they installed and used during the 90-day period from April 2011 to July 2011 possessed basic EHR functionalities, but few other capabilities. In other words, following the CMS incentive program announcement, these hospitals swiftly implemented basic, rudimentary EHR products, and, having barely used them for just the required three months, promptly filed their attestations and claimed their incentives.

Another meaningful pattern is evident in the numbers for October 2011, just past the end of CMS' 2011 reporting year for hospitals. A shown in Table 6, the number of attested systems spiked dramatically relative to the preceding month, from 39 to 185 , with large simultaneous drops in system functionalities, for three of the five factors. Again, the implication is that a number of other hospitals had moved to cash in on year 


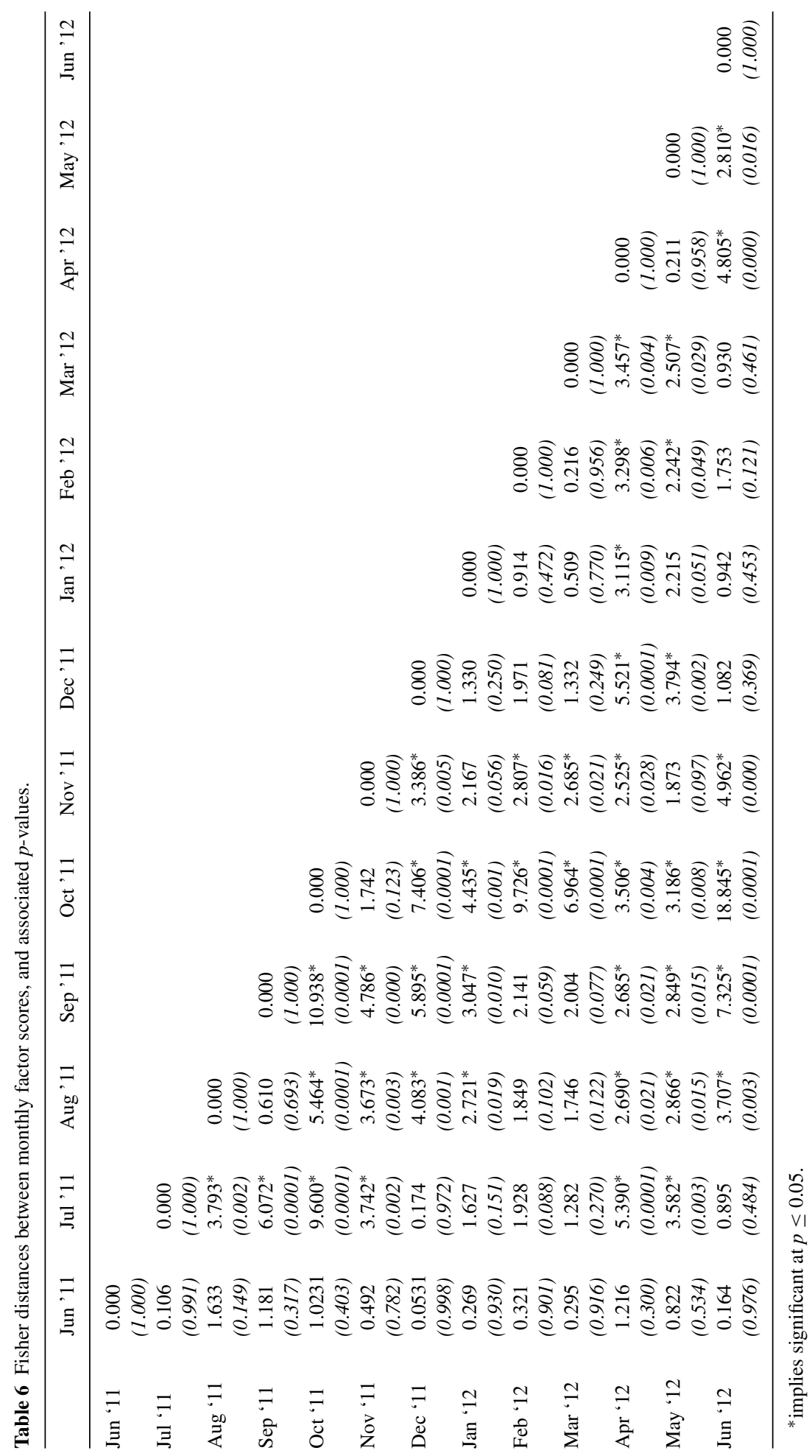


Table 7 Summary of research study.

$\square$ Objective: To determine whether and how the Medicare EHR Incentive Program has successfully influenced the adoption of EHR systems in the inpatient health care setting.

$\square$ Research Proposition: "Over a period of one year since its inception, the CMS Medicare EHR Incentive Program has significantly influenced the adoption of EHR systems in inpatient hospitals."

\section{$\square$ Methodology}

- Overall Approach: To look for meaningful linkages between key dates in the timeline of the incentive program, and the evolving functionalities of modular EHR systems implemented and attested by various hospitals over time.

- Rationale: Significant functionality variations around key dates would indicate a general awareness of the timeline among hospitals, which would imply the presence of a market response.

- Key Assumption: Attestations of EHR products represent a reasonable proxy for measuring EHR adoption.

- Data Sets

○ First Data Set: Attestations filed with CMS by inpatient hospitals, to the "meaningful use" of ONC-certified, modular EHR products, between June 2011 and June 2012.

- Second Data Set: A searchable online database of specific certification criteria (functionalities) met by each ONC-certified, modular EHR product.

- Analysis:

o Reduced the superset of 32 functionalities collectively present in modular EHR products, into fewer, more cohesive categories.

- Started with first data set comprising 81 modular EHR products attested by 549 hospitals.

- Based on information looked up from second dataset, used binary (dummy) variables to indicate presence/absence of each functionality in each product.

- Applied exploratory factor analysis to resulting dummy variable set of 81 records and 32 columns -5 factors extracted.

○ Characterized the 549 attested systems in terms of 5 factor strengths.

o For each system, averaged out the dummy variables under each factor, to compute factor strengths

- Analyzed changing factor strength patterns in attested systems over a 13-month period.

- For each attestation month, factor strengths of systems attested in that month were averaged out, to build monthly factor profiles.

- Conducted profile analysis to identify inflection/change points in 13-month profile of 5 factor strengths, by employing following multidimensional tests:

- Statistical comparison of monthly profiles, to check for evidence of parallelism (similarities), using Wilks' Lambda test with Rao's approximation.

- Upon rejection of parallelism, detection of specific time periods during which changes in factor strengths were statistically significant, by computing "between-class" Fisher distance values for each of 78 unique pairs of months.

- Ascribed contextually meaningful interpretations to statistically significant time periods of changes in factor strengths, by mapping such time periods on key milestones and events in incentive program timeline.

$\square$ Findings: The functionality profiles of modular EHR products attested from one month to the next evolved in a manner consistent with key dates and events in the incentive program.

2011 incentives, despite the nascent functionalities of their EHR systems. Similar drops in system functionalities are also apparent after every 90-day period following the October spike-in January 2012 and April 2012. Also noteworthy is a minor attestation spike in February 2012 following the CMS announcement of proposed Stage 2 rules. This spike was characterized by a selective rise in CORE EHR functionalities similar to the one in 
August 2011. Once again, while all these patterns imply that hospitals have responded to the EHR incentive program by implementing new functionalities, they also convey their intent to extract maximum leverage from the payments system as these functionalities represent the bare minimums necessary to achieve just enough compliance with "meaningful use" requirements.

These findings, therefore, provide conditional support for this study's research proposition, in that the Medicare EHR Incentive Program has significantly influenced the specific functionalities of modular EHR systems implemented in hospitals. On the one hand, the program appears to have encouraged more hospitals to acquire EHR systems. On the other, however, it also appears to have spawned a trend to collect incentive payments as soon as possible, particularly among hospitals with newly implemented, barebones EHR functionalities. If the program's original intent was to bring as many hospitals as possible to this baseline, the findings may be construed as evidence of its spectacular success. Conversely, if the intent was to set hospitals on a longer journey toward more complete EHR functionalities, its success remains as yet undetermined. Given that there was no particular disincentive built into the program for early attestation, many hospitals chose to do so after implementing basic EHR functionalities. Because the modularity of EHR systems makes it possible to grow them by adding newer functionalities over time, it is quite possible that the installed systems will continue to evolve naturally in the future. In that case, the program's real outcomes will hinge largely on implementing hospitals' future actions.

\section{LIMITATIONS}

This article concludes with an acknowledgement of the study's limitations, which should serve as a tempering perspective on its findings. First, the dataset selected for analysis represents a secondary, public source of information, whose accuracy and reliability the authors had no control over whatsoever. Further, the actual dataset used here is a snapshot of the broader, master dataset, picked at a random time in its evolutionary growth. Because the master database continued to grow in the background, even as the results presented here were being prepared, it is possible that the full, complete dataset may have yielded somewhat different conclusions. Second, the extrapolation of these results to the larger population of all hospitals could be presented with greater confidence if the authors had some way of comparing key attributes of attesting hospitals in the sample to those of nonattesting hospitals outside of the sample. However, this was not feasible because of the nonidentifiable nature of records in the attestation sample.

Third, this study uses attestation as a proxy measure or substitute for evaluating EHR adoption. An inherent risk of using a proxy measure lies in the possibility that the proxy does not adequately capture the construct of interest, and the same is true here. Fourth, although the implications of the findings are based on what the authors believe to be sound logical reasoning, the fact is that with all such interpretations, there is always the possibility of alternative explanations, including the objection that coincident events do not necessarily imply the presence of a causal relationship. Finally, it could be argued that it is not sufficient to study attested EHR product attributes alone, and that any research study on this subject should also investigate how implemented product attributes have impacted hospital efficiency and/or effectiveness. However, given the nonidentifiable nature of the records in the attestation dataset, this is not within the feasible scope of the study, but would constitute an excellent objective for a future follow-up investigation. 


\section{REFERENCES}

Centers for Medicare \& Medicaid Services. 2010. "Medicare \& Medicaid EHR incentive program: Meaningful use stage 1 requirements overview" [PowerPoint slides]. Retrieved from CMS Website https://www.cms.gov/Regulations-and-Guidance/Legislation/ EHRIncentivePrograms/downloads/MU_Stage1_ReqOverview.pdf.

DesRoches, C. M., C. Worzala, M. S. Joshi, P. D. Kralovec, and A. K. Jha. 2012. "Small, nonteaching, and rural hospitals continue to be slow in adopting electronic health record systems." Health Affairs 31(5):1092-1099.

Furukawa, M. F., T. S. Raghu, and B. B. M. Shao. 2010. "Electronic medical records and cost efficiency in hospital medical-surgical units." Inquiry-Excellus Health Plan 47(2): $110-123$.

Hamelburg, M. 2009. "EHR and HIT incentives in the American Recovery and Reinvestment Act." Intellectual Property \& Technology Law Journal 21(6):7-13.

Health Information Technology: Initial Set of Standards, Implementation Specifications, and Certification Criteria for Electronic Health Record Technology; Final Rule, 75 Federal Register 44590 (proposed July 28, 2010).

Hillestad, R., J. Bigelow, A. Bower, F. Girosi, and E. Al. 2005. "Can electronic medical record systems transform health care? Potential health benefits, savings, and costs." Health Affairs 24(5):1103-1117.

Hochstadt, B., and D. Keyt. 2009. "Health care IT: Supporting cost efficiencies in tough times." Benefits Quarterly 25(4):7-9.

Kazley, A. S., M. L. Diana, and N. Menachemi. 2011. "The agreement and internal consistency of national hospital EMR measures.” Health Care Management Science 14(4):307-313.

Song, P. H., A. S. McAlearney, J. Robbins, J. S. McCullough, and B. T. Smith. 2011. "Exploring the business case for ambulatory electronic health record system adoption." Journal of Healthcare Management 56(3):169-180.

Tabachnick, B. G., and L. S. Fidell. 2013. Using multivariate statistics (6th ed.). Boston: Allyn and Bacon.

Wolf, L., J. Harvell, and A. K. Jha. 2012. "Hospitals ineligible for federal meaningful-use incentives have dismally low rates of adoption of electronic health records." Health Affairs 31(3):505-513.

\section{BIOGRAPHIES}

Rajesh Mirani is an associate professor of information systems at the Merrick School of Business, University of Baltimore. His current research interests are oriented toward performance and public policy implications of infrastructural IT projects such as electronic health records in hospitals and "steady state" IT investments in the federal government. Dr. Mirani has published in a variety of highly regarded journals such as Decision Sciences, Journal of Management Information Systems, Information \& Management, MIS Quarterly, ACM Transactions on Management Information Systems, and Journal of Information Technology. He holds a PhD from the University of Pittsburgh.

Anju Harpalani is a licensed pharmacist, board-certified in ambulatory care, with more than 20 years of experience in various practice settings including community pharmacy, long term care, and managed care. Dr. Harpalani has experience in pharmacy workflow processes, plan benefit administration, and the Medicare Part D coverage determination and appeals process. She also has an interest and research experience in hospital electronic health records. As a healthcare consultant, Dr. Harpalani currently works on Medicare Part D issues where she provides pharmacy expertise. She holds a PharmD from the University of Florida and a BS in Pharmacy from SNDT University, India. 